\title{
ATIVIDADE ANTIBACTERIANA DE EXTRATO AQUOSO DA CASCA DE NOZ-PECÃ [CARYA ILLINOINENSIS (WANGENH.) C. KOCH]
}

Alexandre Carvalho de Moura ${ }^{1}$

Dalila Moter Benvegnú ${ }^{2}$

Gleisy Coser de Brito ${ }^{3}$

Izabel Aparecida Soares ${ }^{4}$

\begin{abstract}
Resumo: A crescente incidência de doenças infecciosas, causadas pelo surgimento de microrganismos multirresistentes às medicações alopáticas, provoca pesquisadores a buscar terapias antimicrobianas alternativas, como a utilização de extratos vegetais. O presente trabalho visou avaliar o potencial antibacteriano do extrato aquoso da casca de noz-pecã [Carya illinoinensis (Wangenh.) C. Koch] sobre bactérias, uma vez que são escassos estudos quanto sua atividade antimicrobiana. $\mathrm{O}$ extrato vegetal bruto das cascas de $C$. illinoensis foi avaliado sobre os microrganismos por meio dos métodos de Determinação da Concentração Inibitória Mínima (CIM), e Difusão em Poço (DP). Verificou-se que o extrato apresentou atividade bactericida para todas as cepas testadas nas concentrações de $15 \%(v / v)$ e $20 \%(v / v)$, com exceção da bactéria Staphylococcus aureus, cujo efeito foi bacteriostático a $15 \%(v / v)$. O potencial do extrato aquoso na terapêutica de doenças infecciosas é evidenciado e incentiva novos estudos que busquem testar sobre outros microrganismos, assim como seus possíveis mecanismos de ação.
\end{abstract}

Palavras chave: Multirresistência bacteriana, Doenças infecciosas, Extrato vegetal.

\section{ANTIBACTERIAL ACTIVITY OF AQUEOUS EXTRACT FROM THE NUTS OF THE NUTS [CARYA ILLINOINENSIS (WANGENH.) C. KOCH]}

\begin{abstract}
The increasing incidence of infectious diseases, caused by the emergence of multiresistant microorganisms to allopathic medications, induce researchers to seek alternative antimicrobial therapies such as the use of plant extracts. This study aimed to evaluate the antibacterial potential of the aqueous extract of nut shells pecans [Carya illinoinensis (Wangenh.) C. Koch] against gram-positive and gram-negative bacterial, since there are few studies as their antimicrobial activity. The gross plant extract of nut shells $C$. illinoensis was obtained and evaluated using the methods Determination of Minimum Inhibitory Concentration (MIC), and Diffusion in Well $(D P)$. It was found that the nut shell pecan extract showed bactericidal activity for all bacterial strains tested in concentrations of 15\% (v/v) and 20\% (v/v), exception of Staphylococcus aureus, which bacteriostatic effect was $15 \%(v / v)$. The potential of the aqueous extract in the treatment of infectious diseases is evident and encourages new studies with other microorganisms, as well as their possible mechanisms of action.
\end{abstract}

Keywords: Multiresistance bacterial, Infectious diseases, Plant extract.

\footnotetext{
${ }^{1}$ Graduado em Ciências Biológicas Bacharelado e Licenciatura pela Universidade Santa Úrsula, Especialista em Análises Clínicas pela Faculdade Assis Gurgac, Mestrado em Microbiologia pela Universidade Estadual de Londrina e Doutorado em Recursos Hídricos pela Universidade Estadual do Oeste do Paraná- UNIOESTE. Atualmente é docente concursado na Universidade Federal da Fronteira Sul - UFFS. Tem experiência na área de Microbiologia e Imunologia, com ênfase em Biologia, Fisiologia e Diversidade de Microrganismos, atuando principalmente nos seguintes temas: Microbiologia ambiental e de Alimentos.

${ }_{2}^{2}$ Possui graduação em Farmácia pela Universidade Federal de Santa Maria (2008) e mestrado (2010) e doutorado em Farmacologia (2012) pela mesma instituição. Atualmente é professora adjunta III da Universidade Federal da Fronteira Sul, onde ministra aulas de bioquímica e farmacologia aos cursos de Graduação em Nutrição e Ciências Biológicas e onde atua como orientadora no Programa de Pós-Graduação em Saúde, Bem-estar e Produção Animal Sustentável na Fronteira Sul.

${ }^{3}$ Acadêmica do curso de Ciências Biológicas-Universidade Federal da Fronteira Sul - Campus Realeza.

${ }^{4}$ Possui graduação em Licenciatura e Bacharelado em Ciências Biológicas pela Universidade Estadual de Maringá (1998), mestrado em Agronomia pela Universidade Estadual de Maringá (2001) e doutorado em Agronomia, área de concentração; Melhoramento Genético, pela Universidade Estadual de Maringá (2005). Foi coordenadora do curso de Ciências Biológicas (2013-2015 - UFFS). Colaboradora no projeto PIBID Institucional desde 2014. Atualmente é professor Associado D (Nível II) da Universidade Federal da Fronteira Sul. Atua na pesquisa com Toxicologia qualidade da água.
} 


\section{Introdução}

Nas últimas décadas, o avanço científico e o desenvolvimento da medicina propiciaram a descoberta de antimicrobianos eficientes para o tratamento de infecções bacterianas diminuindo assim, substancialmente o número de mortes causadas por doenças infecciosas. Entretanto, o aumento indiscriminado do uso de antibióticos, vem contribuindo para seleção de cepas de bactérias resistentes a esses medicamentos (SILVEIRA et al., 2006). O uso intenso e sem controle de antibióticos, aumenta a pressão seletiva e facilita a obtenção de mecanismos de resistência, o qual se tornou uma consequência natural, inevitável e irreversível da adaptação da célula bacteriana a exposição aos antibióticos. Esta resistência antimicrobiana tornou-se um dos principais problemas de controle aos microrganismos, preocupando seriamente as autoridades em saúde pública no mundo, afetando todos os países, sendo eles desenvolvidos ou não. (SANTOS, 2004).

Conforme relatório de verificação global da resistência antimicrobiana da WHO (2011), o surgimento de superbactérias ou bactérias multirresistentes, mostra-se como um fato global e que está pondo em risco o tratamento de infecções de importância médica comuns principalmente em ambientes hospitalares. Sem ações urgentes e coordenadas, deduz-se que futuramente infecções comuns e ferimentos leves, anteriormente tratáveis, poderão voltar a causar óbitos (WHO, 2014).

Com o desenvolvimento científico e da indústria farmacêutica, o uso de plantas medicinais perdeu espaço para os medicamentos sintéticos. Entretanto, o alto custo destes fármacos, o difícil acesso, os efeitos colaterais e, atualmente, o uso crescente de produtos de origem natural, contribuíram para o reaparecimento do uso de plantas medicinais, as quais são constituídas por misturas complexas de substâncias bioativas. Porém, em plantas medicinais, ao contrário do medicamento sintético, não há substância ativa isolada, o que dificulta informações sobre sua ação farmacológica e sua biodisponibilidade (FARIAS, 2016). Nesse sentido, a demanda por novos estudos de compostos antimicrobianos configura-se como um desafio aos pesquisadores, que crescentemente buscam fármacos alternativos, como os de origem vegetal, visando um efeito antimicrobiano sobre os agentes infecciosos de importância médica (SANDES, DI BLASI, 2000; NOVAIS et al., 2003; DUARTE, 2006).

A obtenção de antimicrobianos de origem vegetal pode advir de diferentes tecidos e 'orgaos vegetais, tais como: caule, raiz - tubérculos, folhas, flores, frutos, cascas e até mesmo da planta inteira (TORO-VAZQUEZ et al., 1999; PRETTO, 2005; ARAÚJO, 2011; PRADO et al., 2009; PRADO, 2013). Entretanto, vale salientar que variações no rendimento e na composição química dos extratos essenciais podem ser influenciadas por questões ambientais, 
técnicas/metodológicas e genéticas do espécime (ARAÚJO, 2011; CASTRO et al., 2008; MILLEZI et al., 2014).

$\mathrm{Na}$ literatura estão descritos muitos estudos in vitro que envolvem a utilização de substâncias com atividades antimicrobianas de origem vegetal, em especial óleos essenciais, cujos resultados evidenciam as discrepâncias descritas acima. SILVA et al. (2009), indicaram atividade antimicrobiana do óleo essencial de canela sobre as cepas de S. aureus e Escherichia coli isoladas de humanos com sinais clínicos. Santurio (2011), constatou maior atividade antimicrobiana do óleo essencial de orégano e menor atividade para o óleo essencial de canela frente aos demais óleos estudados para a $E$. coli isolados de suínos, aves e bovinos.

A atividade antibacteriana do óleo essencial do manjericão foi testada frente a sorogrupos de E. coli enteropatogênicas (EPEC) isolados de alfaces orgânicas e hidropônicas. Todos os sorogrupos testados apresentaram sensibilidade frente a ação do óleo essencial (MARTINS et al., 2010). A eficácia da ação antibacteriana dos óleos essenciais também varia significativamente em função do microrganismo (PRETTO, 2005; SILVA et al., 2009; SANTURIO, 2011).

O Brasil é um país que possui um enorme potencial para o desenvolvimento de estudos e de descobertas de plantas medicinais e de fármacos à base delas, pois conta com cerca de 55.000 de um total de 350.000 e 550.000 das espécies medicinais estão catalogadas, facilitando o aproveitamento do potencial curativo dos vegetais para o tratamento de doenças no país. Essa capacidade de desenvolvimento e estudos deve-se ao fato de que o ecossistema amazônico é detentor de uma das regiões de maior biodiversidade do planeta, com $25 \%$ da flora mundial, a qual apresenta inúmeras espécies vegetais com propriedades medicinais relatadas e outras em que seus efeitos terapêuticos ainda são desconhecidos (SANTOS et al., 2014; BONIFÁCIO, 2014).

Dentre essas espécies vegetais, está a noz pecã Carya illinoinensis (Wangenh.) K. Koch a qual pertence à família Juglandaceae e é originária da América do Norte. No Brasil a noz pecã é produzida principalmente na região sul e beneficiada por indústrias localizadas nos estados do Rio Grande do Sul e de São Paulo. Seus frutos amadurecem e caem sem o exocarpo no outono e a semente ou amêndoa (noz) é envolta por tegumento (LORENZI et al., 2006). Novos trabalhos destacam o potencial de extratos de noz-pecã ou noz-americana [Carya illinoinensis (Wangenh.) C. Koch] quanto sua atividade antimicrobiana

Segundo Prado (2013), durante o processamento industrial das nozes-pecã há uma grande sobra de cascas, as quais são embaladas e comercializadas como chá. As pessoas residentes no sul do Brasil costumam consumir o produto considerando-o benéfico para saúde, cujos motivos certamente referem-se ao potencial antioxidante, já estudados pela autora (PRADO, 2008; 
PRADO et al., 2009). O extrato aquoso de cascas de nozes-pecã evidenciou redução de danos oxidativos, induzidos pela exposição à fumaça do cigarro e dos sintomas ocasionados pela sua retirada (RECKZIEGEL et al., 2011). A solução aquosa, também apresentou potencial no tratamento de doenças hepáticas ligadas ao consumo de etanol (MULLER et al., 2013).

Los Angeles et al., (2012) e Cruz-Vega et al., (2008), estudaram e constataram atividade antibacteriana do extrato hexânico da casca de noz-pecã sobre o Mycobacterium tuberculosis. Para este último trabalho, os extratos aquosos comparados com outros solventes utilizados, não foram considerados aconselháveis para obtenção de princípios antimicobacterianos de espécies vegetais.

Cano-cabrera et al., (2009) estudaram o extrato aquoso da casca de noz-pecã ( $C$. illinoinensis), e evidenciaram seu considerável pontencial fungicida em 100\% para Fusarium oxysporum, Penicillium pinophylum, Aspergillus ustus, Aspergillus fumigatus e Mucor griseocyanu. Osorio et al., (2010) ao avaliarem extratos polifenólicos da casca de noz-pecã constataram sua eficácia de $100 \%$ para inibição do crescimento fúngico de Pythium sp., Colletotrichum truncatum, Colletotrichum coccodes, Fusarium sambucinum, Rhizoctonia solani, $75 \%$ de inibição para Fusarium solani e 50\% para Alternaria alternata e Fusarium verticillioides. Prado (2013) identificou e avaliou a atividade antimicrobiana de compostos fenólicos da casca de noz-pecã. Todos os extratos, inclusive o aquoso, apresentaram potencial bactericida para Listeria monocytogenes, Staphylococcus aureus, Vibrio parahaemolyticus e Bacillus cereus.

Apesar de evidências do alto potencial antioxidante dos extratos de casca de nozes-pecã, estudos sobre a atividade antimicrobiana são escassos, no entanto, apontam uma alternativa terapêutica para o tratamento de infecções. Desse modo, o presente trabalho avaliou o potencial antibacteriano do extrato aquoso da casca de noz-pecã sobre um grupo de diferentes cepas (linhagens) bacterianas gram-positivas e gram-negativas.

\section{Material e Métodos}

\section{Microrganismos utilizados}

Os microrganismos testados foram adquiridos pelo laboratório de Microbiologia da UFFS campus Realeza/PR, sendo 2 cepas de bactérias gram-positivas (Bacillus cereus ATCC 14579 e Staphylococcus aureus ATCC 25923) e 3 gram-negativas (Escherichia coli ATCC 25922, Klebsiella pneumoniae ATCC 700603 e Pseudomonas aeruginosa ATCC 27853). 


\section{Obtenção do Extrato Aquoso Bruto}

As cascas de noz-pecã foram gentilmente doadas pela empresa Pecantea Divinut, de Cachoeira do Sul - RS.

O extrato bruto das cascas foi obtido no laboratório de Química Orgânica e Bioquímica da UFFS campus Realeza/PR. Primeiramente as cascas foram lavadas com água corrente e posteriormente mantidas em uma estufa de secagem e esterilização com circulação e renovação de ar (modelo AL-102/480 da marca AmericanLab) durante $24 \mathrm{~h}$ a $60{ }^{\circ} \mathrm{C}$. As cascas foram trituradas em um moinho de facas tipo Willye (AL-032S) em peneira de 20 mesh, até obtenção de um pó finíssimo, que foi pesado a $50 \%(\mathrm{~m} / \mathrm{v})$ e mantido por infusão em água destilada durante $5 \mathrm{~h}$ pelo método de extração soxhlet. Durante este processo, o extrato foi mantido ao abrigo de luz e armazenado em frasco âmbar. Esta metodologia foi baseada em Trevisol et al., (2011), com algumas adaptações relacionadas à temperatura de secagem e método de extração.

\section{Avaliação antibacteriana do extrato}

Após obtenção do extrato bruto das cascas, a atividade antibacteriana foi avaliada pelo método de Difusão em Poço (DP) e microdiluição em caldo para a determinação da Concentração Inibitória Mínima (CIM) (DE BONA et al., 2014).

A CIM foi realizada conforme a metodologia descrita no documento National Committee for Clinical Laboratory Standards - NCCLS (2003). As diferentes cepas bacterianas foram inoculadas em meio de enriquecimento Brain Heart Infusion (BHI) e incubados $35 \pm 2{ }^{\circ} \mathrm{C}$ por 24 horas. Em seguida, foram diluídas em solução salina 0,9\% até atingir a escala de 1,5 x $10^{8}$ UFC/ml de MacFarland. A partir deste momento, diluiu-se em 1:100 em caldo Müller-Hinton (MH). Distribui-se caldo $\mathrm{MH}$ em poços de uma placa de microdiluição de 96 poços. Os extratos foram diluídos para as concentrações finais nos poços de $5 \%(\mathrm{v} / \mathrm{v}), 10 \%(\mathrm{v} / \mathrm{v}), 15 \%(\mathrm{v} / \mathrm{v})$, e $20 \%$ $(\mathrm{v} / \mathrm{v})$ e $10 \mu \mathrm{L}$ da bactéria anteriormente preparada. Como controle positivo foram adicionados cloranfenicol na concentração de $30 \mathrm{mg} / \mathrm{mL}$ ao caldo $\mathrm{MH}$; e para o controle negativo, $120 \mu \mathrm{L}$ de água destilada esterilizada no lugar do extrato. As microplacas foram incubadas a $37{ }^{\circ} \mathrm{C}$ por 24 horas, em condições de aerobiose e o teste feito em triplicata conforme metodologia descrita por De Bona et al., (2014), com adaptações descritas acima.

Após incubação, analisou-se e relacionou-se a turbidez do meio com o crescimento microbiano, onde a presença de turvação equivaleu ao crescimento bacteriano e ausência de turvação representou o não crescimento (BLACK, 2002; ANVISA, 2006; DE BONA et al., 2013; TORTORA et al., 2012). A CIM foi descrita como a quantidade mínima do extrato vegetal suficiente para uma ação bactericida ou bacteriostática (AYRES et al., 2008). 
A determinação da Concentração Bactericida Mínima (CBM) foi realizada segundo Santúrio et al., (2007), a qual foi retirado $10 \mu \mathrm{L}$ dos poços onde não haviam turvação aparente e semeou-se na superfície do ágar $\mathrm{MH}$. Incubou-se as placas a $37^{\circ} \mathrm{C}$ por 48 horas. Desse modo, definiu-se a CBM como a menor concentração do extrato analisado capaz de matar a cepa bacteriana como $15 \%(\mathrm{v} / \mathrm{v})$.

O teste de DP foi feito com base nos dados do Clinical and Laboratory Standards Institute - CLSI (2009), com modificações. Este método consistiu na realização de seis orifícios de 6 mm de diâmetro no meio de cultura ágar MH em placas de Petri, utilizando-se de um molde para formar os poços.

As placas foram inoculadas na superfície com os microrganismos com o uso de um suabe esterilizado e os poços foram preenchidos com $40 \mu \mathrm{L}$ do extrato na concentração a ser testada. As placas foram incubadas a $37^{\circ} \mathrm{C}$ por 24 horas. Por fim, mediu-se com régua milimétrica o halo de inibição do crescimento (DE BONA et al., 2014). As médias dos valores observados nos ensaios de difusão em ágar foram avaliadas conforme seus respectivos desvios padrões.

\section{Resultados e Discussões}

Os resultados do bioensaio da CIM, indicam que dentre as quatro concentrações testadas do extrato aquoso de $C$. illinoinensis sobre as diferentes cepas bacterianas, as concentrações de $15 \%$ (v/v) e $20 \%$ (v/v) apresentaram atividade antibacteriana em $80 \%$ e $100 \%$ das cepas testadas, respectivamente. Em relação às concentrações de $5 \%$ (v/v) e $10 \%$ (v/v), não foram observadas atividades antibacterianas, não havendo inibição de crescimento dos microrganismos. Houve atividade bactericida para todas as cepas bacterianas, exceto para $S$. aureus, o qual apresentou atividade bacteriostática na concentração de $15 \%$ (v/v) do extrato. Em relação à atividade antibacteriana nos diferentes grupos de bactérias (Gram + e Gram -), não houve diferença significativa a 5\% de significância (Tabela1).

Tabela 1. Determinação da Concentração Inibitória Mínima (CIM) e Concentração Bactericida mínima $(\mathrm{CBM})(\mu \mathrm{L} / \mathrm{mL})$ do extrato vegetal bruto das cascas de $C$. illinoensis frente as cinco cepas bacterianas estudadas e porcentagem de inibição.

\begin{tabular}{lllll}
\hline & \multicolumn{4}{l}{ CIM $(\boldsymbol{\mu L} / \mathbf{m L})$} \\
\cline { 2 - 5 } Microrganismos & $\mathbf{5 \%}$ & $\mathbf{1 0 \%}$ & $\mathbf{1 5 \%}$ & $\mathbf{2 0 \%}$ \\
\hline S. aureus & - & - & $130 *$ & 110 \\
E. coli & - & - & 130 & 110 \\
K. pneumoniae & - & - & 130 & 110 \\
B. cereus & - & - & 130 & 110 \\
P.aeruginosa & - & - & 130 & 110 \\
\% de inibição & $0 \%$ & $0 \%$ & $80 \%$ & $100 \%$ \\
\hline
\end{tabular}


Legenda: *= Atividade bacteriostática; - = Ausência de inibição nas concentrações testadas.

Todas as concentrações de $15 \%(\mathrm{v} / \mathrm{v})$ e $20 \%(\mathrm{v} / \mathrm{v})$ mostraram atividade antibacteriana para as cepas de E. coli, K. pneumoniae, B. cereus e P. aeruginosa. Prado (2013) também analisou a CIM para a metodologia de infusão, para S. aureus, Vibrio parahaemolyticus e B. cereus, a qual mostrou-se efetiva sobretudo para $V$. parahaemolyticus. No entanto, a autora utilizou o solvente orgânico, dimetilsulfóxido (DMSO) para diluir os extratos. O DMSO, aprótico e altamente polar, "apresenta alta afinidade por hidrogênios em ligações polares, formando ligações com estes mais fortes que as formadas entre as moléculas de água" (CARDOSO, 2011, p.344), o que provavelmente explica ausência de precipitação do extrato analisado neste estudo e sua ação mais efetiva contra os microrganismos.

Ao descrever o perfil de compostos fenólicos contidos nos diferentes extratos (infusão, infusão seca em spray dryer e extrato etanólico) da casca de noz-pecã através de Cromatografia Líquida de Alta Eficiência (CLAE), Prado (2013) identificou três ácidos fenólicos (gálico, clorogênico, $p$-didroxibenzoico) e dois compostos da classe dos flavonoides, subcasse flavan-3ol (epigalocatequina e epicatequina galato), sugerindo a possibilidade de existência de outros compostos. Também foram identificados altos teores de compostos fenólicos totais e taninos condensados na infusão de casca de noz-pecã (PRADO et al., 2009)

O processo de obtenção de extratos vegetais requer atenção em aspectos, como: características do material vegetal, solvente escolhido e a metodologia. A água e as misturas hidroalcoólicas estão entre os solventes mais utilizados e os tipos de substâncias comumente extraídos por estes são, saponinas e taninos (CHOZE, 2004).

Diferentes trabalhos, com outros extratos vegetais apontam a relação entre a presença de compostos fenólicos e atividade antimicrobiana. Nascimento et al., (2000) indicaram ação antibacteriana de extratos hidroalcoólicos vegetais e fitofármacos, constatando uma atividade efetiva principalmente para os extratos de jambolão, cravo, romã e tomilho, para S. aureus, K. pneumoniae e $P$. aeruginosa, devido aos elevados teores de taninos e flavonoides em suas composições. Contudo, E. coli mostrou-se resistente aos extratos de plantas testados, sendo suscetível apenas para os ácidos benzoico e cinâmico.

Assim como o presente estudo, Ferreira et al., (2011), através da CIM, obtiveram resultados bastante efetivos do extrato da casca de Rhizophora mangle para as cepas Gramnegativas, ao avaliar o potencial antibacteriano de extratos brutos (casca, folha e raiz) sobre microrganismos diversos, dentre eles: S. aureus, E. coli, K. pneumoniae e P. aeruginosa. A capacidade antibacteriana de $R$. mangle coincide com dados da literatura de outro membro da família Rhizophoraceae, no qual são relatados, em particular na casca, uma grande quantidade de 
compostos, como: taninos hidrosolúveis, polifenóis, epicatequina, catequina, ácidos clorogênico, gálico, elágico, além de taninos condensados. Sendo todos estes grupos efetivos na atividade antimicrobiana, inclusive para S. aureus.

Além de sua já conhecida ação antioxidante, os flavonoides que fazem parte de um grande grupo de metabólitos secundários de plantas, principalmente dentre as superiores, caracterizam-se como compostos polifenólicos, havendo estudos que confirmam sua atividade antimicrobiana para os microrganismos $S$. aureus e $P$. aeruginosa comuns a esta pesquisa (RAUHA et al., 2000). Ahmad e Beg (2001), ao avaliarem extratos etanólicos de vegetais tradicionalmente utilizados na medicina, identificaram dentre os extratos ativos, a presença de fenóis, taninos e flavonoides como principais componentes ativos.

Nota-se associação entre a ação antimicrobiana e a presença de compostos fenólicos como os taninos e flavonoides na maioria dos referenciais, cuja literatura já tenha identificado tais compostos nos extratos avaliados. De uma forma sucinta, os taninos aparentam interferir no crescimento bacteriano de diferentes modos, como: na inibição de enzimas extracelulares microbianas, através de danos na membrana, na privação de substratos essenciais para seu crescimento, na ação direta sobre o seu metabolismo por meio da vedação da fosforilação oxidativa e complexação de íons metálicos em ambiente de crescimento bacteriano (SERRANO et al., 2009; SCALBERT et al, 1991).

No teste de DP, houve inibição do crescimento bacteriano para todas as cepas estudadas, inclusive para as concentrações de $5 \%(\mathrm{v} / \mathrm{v})$ e $10 \%(\mathrm{v} / \mathrm{v})$, as quais não haviam demonstrado efetividade no teste CIM. Ao comparar os resultados obtidos da ação antibacteriana entre as diferentes cepas bacterianas obteve-se halos de inibição variando de 9,16 mm a 10,8 mm para o grupo das Gram positivas e 8,88 mm a 10,6 mm para Gram negativas, não havendo diferença significativa dentro de cada grupo. Também não houve diferença significativa na ação antibacteriana quando comparados os halos de inibição do extrato sobre as bactérias dos dois grupos (Tabela 2).

Tabela 2. Comparação entre as médias das medidas dos halos de inibição do crescimento das bactérias Gram + e Gram - obtidas pela metodologia de Difusão em Poço (DP), utilizando extrato aquoso em 4 concentrações diferentes.

\section{Concentrações do Extrato Tamanho do halo de inibição (mm)}

\begin{tabular}{cccc}
\hline & Gram + & & Gram- \\
\cline { 2 - 3 } $10 \%$ & $9,16 \pm 0,98 \mathrm{a}$ & & $8,88 \pm 1,45 \mathrm{~A}$ \\
$15 \%$ & $10,3 \pm 0,51 \mathrm{a}$ & & $9,55 \pm 1,33 \mathrm{~A}$ \\
$20 \%$ & $10,8 \pm 0,75 \mathrm{a}$ & & $10,1 \pm 1,36 \mathrm{~A}$ \\
\hline
\end{tabular}

Legenda: $\mathrm{mm}=$ milímetro - unidade de medida utilizada; 
Letras distintas na mesma coluna representam grupos bacterianos diferentes (gram-positivas e gram-negativas).

Para ambas as metodologias testadas, têm-se interesse em trabalhar com maiores concentrações do extrato aquoso, a fim de comparar sua real efetividade na ação antibacteriana.

No presente trabalho foram observados diâmetros de inibição menores do que os encontrados por Prado (2013) para o teste de DP, uma vez que as médias dos diâmetros de maior inibição das concentrações de $15 \%$ (v/v) e $20 \%$ (v/v) ficaram entre 4,6 a 5 mm. Enquanto que a autora observou diâmetros médios de halos de inibição entre 7 a $11 \mathrm{~mm}$, com um grupo diferenciado de microrganismos, dentre eles: Staphylococcus aureus e Bacillus cereus comuns a esta pesquisa.

As discrepâncias observadas entre o presente estudo e o de Prado (2013), podem estar relacionadas, além dos períodos e métodos de processamento das nozes, ao fato de o extrato ter apresentado baixa diluição em água, levando-o a precipitar no fundo dos poços e consequentemente reduzir a solubilidade de seus compostos fenólicos no solvente utilizado, sugerindo escassez dos componentes ativos capazes de inibir o crescimento bacteriano nas concentrações testadas. Outros fatores que podem estar relacionados às divergências nos resultados, dizem respeito às diferenças na metodologia experimental, como: a ordem de alguns procedimentos, além de temperaturas e períodos de incubação diferenciados.

\section{Conclusões}

Por meio deste estudo, pode-se observar o potencial antibacteriano do extrato aquoso da casca de noz-pecã $C$. illinoinensis frente às bactérias testadas. Os resultados in vitro obtidos sugerem uma possível utilização deste extrato na terapêutica de doenças infecciosas, incentivando novos estudos que busquem testar as propriedades deste inóculo natural e de fácil acesso, assim como estratégias metodológicas que visem contribuir para uma exatidão no seu estudo e avaliação frente a outros microrganismos. Portanto, esta pesquisa está sujeita a continuidade com a realização de novos bioensaios.

\section{Agradecimentos}

Os autores agradecem à Universidade Federal da Fronteira Sul (UFFS) - campus Realeza/PR por ceder os laboratórios para realização dos bioensaios e à empresa Pecantea Divinut, de Cachoeira do Sul - RS, pelo fornecimento das cascas de nozes-pecã para realização desta pesquisa. 


\section{Referências}

AGÊNCIA NACIONAL DE VIGILÂNCIA SANITÁRIA - ANVISA. Controle interno da Qualidade para testes de sensibilidade a Antimicrobianos. Termo de Cooperação 37. 2006. Agência Nacional de Vigilância Sanitária / Ministério de Saúde e a Organização Pan-Americana da Saúde/Organização Mundial da Saúde. Disponível em: <http://www.anvisa.gov.br/servicosaude/manuais/manual_testes_antimicrobianos.pdf $>$. Acesso em: 15 out. 2014.

AGÊNCIA NACIONAL DE VIGILÂNCIA SANITÁRIA - ANVISA. Mod. 3. Resistência microbiana $e$ impacto clínico, 2007. Disponível em: $<$ http://www.anvisa.gov.br/servicosaude/controle/rede_rm/cursos/rm_controle/opas_web/modulo 3/mecanismos.htm>. Acesso em: 24 jun. 2014.

AHMED, M. K.; BEG, A. Z. Antimicrobial and phytochemical studies on 45 Indian medicinal plants against multi-grugs resistant human pathogens. Journal of Ethnopharmacology, Limerick, V. 74, p. 113-123, 2005.

ARAÚJO, I. S. Atividade antimicrobiana de plantas aromáticas que ocorrem no estado do Pará. 2011, 103p. Dissertação (Mestrado em Biotecnologia) - Universidade Estadual de Feira de Santana, Feira de Santana - BA, 2011.

AYRES, M. C.C; BRANDÃO, M. S.; VIEIRA-JUNIOR, G. M. MENOR, J. C. A. S.; SILVA, H. B; SOARES, N. J. S.; CHAVES, M. H. Atividade antibacteriana de plantas úteis e constituintes químicos da raiz de Copernicia prunifera. Rev. Bras. Farmacogn. vol.18, n.1, p. 90-97, 2008. ISSN 0102-695X.

BONIFÁCIO, B. V.; Atividade antimicrobiana in vitro de extratos hidroetanólicos de Astronium sp incorporados ou não em sistemas nanoestruturados. 99 pág. Faculdade De Ciências Farmacêuticas Programa De Pós-Graduação Em Ciências Farmacêuticas Araraquara - SP, 2014.

BLACK, J.G (4 Ed.). Microbiologia: fundamentos e perspectivas. Rio de Janeiro: Guanabara Koogan, 2002. 829 p.

CANO-CABRERA, J. C.; ALVARADO-ESPINOSA, J.; ILINA, A.; AGUILAR-GONZÁLES, C. N.; MARTÍNEZ-HERNÁNDEZ, J. L.. Efecto de extractos acuosos de Larrea tridentata, A. lecheguilla Y cáscara de nuez (Carya illinoinensis) contra micro-organismos fúngicos. In: CONGRESSO NACIONAL DE BIOTECNOLOGIA Y BIOINGENIERÍA, 2009.

CARDOSO, M. F. C. Métodos de Preparação Industrial de Solventes e Reagentes Químicos Dimetilssulfóxido (CAS No. 67-68-5). Revista Virtual de Química. vol. 3, n. 4, p. 344-352, 2011. ISSN 1984-6835.

CAStro, N. E. A.; CARVAlho, G. J.; CARdoso, M. G.; PIMENTEl, F. A.; CORREA, R. M.; GUIMARÃES, L. G. L.. Avaliação de rendimento e dos constituintes químicos do óleo essencial de folhas de Eucalyptus citriodora Hook. colhidas em diferentes épocas do ano em municípios de Minas Gerais. Rev. Bras. Pl. Med., Botucatu, v.10, n.1, p.70-75, 2008. Disponível em: < http://sbpmed.org.br/download/issn_08_1/artigo10_v10_n1_p70a75.pdf>. Acesso em: 19 abr. 2015.

CHOZE, R. Técnicas de Separação e Identificação Empregadas na Análise de Produtos Naturais de Plantas. 2004, 40f. Trabalho de Conclusão de Curso (Graduação em Química) Universidade Federal de Santa Maria - RS, 2004.

CLINICAL AND LABORATORY STANDARDS INSTITUTE - CLSI. Padrões de desempenho para testes de suscetibilidade antimicrobiana em disco; Aprovado 10 Edição pelo Standand. Wayne, CLSI documento M02-A10, 2009. 
CRUZ-VEGA, D. E.; VERDE-STAR M. J.; SALINAS-GONZÁLEZ, N.; ROSALESHERNÁNDEZ, B.; ESTRADA-GARCÍA, I.; MENDEZ-ARAGÓN, P.; CARRANZAROSALES, P.; GONZÁLEZ-GARZA, M.T.; CASTRO-GARZA, J. Antimycobacterial activity of Juglans regia, Juglans mollis, Carya illinoensis and Bocconia frutescens. Phytotherapy Research, v. 22, p. 557-559, 2008.

DE BONA, E. A. M.; PINTO, F. G. da S.; BORGES, A. M. C.; SCUR, M. C.; FRUET, T. K; WEBER, L. D.; ALVES, L. F. A.; MOURA, A. C. DE. Avaliação da Atividade Antimicrobiana de Extratos Vegetais Frente a Sorovares de Salmonella spp. de Origem Avícola. UNOPAR Cient Ciênc Biol Saúde. v.15, n. 1, p.41-46, 2013. DOI: 10.1590/1808-1657001192012.

DE BONA, E. A. M.; PINTO, F. G. da S.; FRUET, T. K; JORGE, T. C. M.; MOURA, A. C. de. Comparação de Métodos para Avaliação da Atividade Antimicrobiana e Determinação da Concentração Inibitória Mínima (CIM) de Extratos Vegetais Aquosos e Etanólicos. Arq. Inst. Biol., v.81, n.3, p. 218-225, 2014. DOI: 10.1590/1808-1657001192012. Disponível em: <http://www.biologico.sp.gov.br/docs/arq/v81_3/218-225.pdf>. Acesso em: 19 abr. 2015.

DUARTE, M. C. T. Atividade antimicrobiana de plantas medicinais e aromáticas utilizadas no Brasil. MultiCiência: construindo a história dos produtos naturais, p.1-16, 2006. Disponível em: < https://www.multiciencia.unicamp.br/artigos_07/a_05_7.pdf>. Acesso em: 19 abr. 2015.

FARIAS, D. S. D. et al; Uso De Plantas Medicinais E Fitoterápicos Como Forma Complementar No Controle Da Hipertensão Arterial. ISSN 1983-4209 - Volume 12 - Número 03 - 2016.

FERREIRA, F.S.; SANTOS, S. C.; BARROS, T. F.; ROSSI-ALVA, J. C.; FERNANDEZ, L. G. Atividade antibacteriana in vitro de extratos de Rhizophora mangle L.. Rev. bras. plantas med. 2011, v.13, n.3, p. 305-310. ISSN 1516-0572. Disponível em: $<$ http://www.scielo.br/scielo.php?script=sci_arttext\&pid=S1516-05722011000300009>. Acesso em: 19 abr. 2015.

FIGUEIRÊDO, F. V. Susceptibilidade a antimicrobianos e resistência plasmidial de cepas de Salmonella spp isoladas de dois estuários do Estado do Ceará, Brasil. 2008. 54f. Tese (Doutorado em Aquicultura) - Universidade Estadual Paulista, Centro de Aquicultura da Unesp, Jaboticabal - SP, 2008.

LORENZI, H.; BACHER, L.; LACERDA, M.; SARTORI, S.. Frutas brasileiras e Exóticas Cultivadas (de consumo in natura). São Paulo: Instituto Plantarum de Estudos da Flora. 2006, $640 \mathrm{p}$.

LOS ANGELES, S. E. M.; ROCÍO, A. R.; ROCÍO, C. R.; RICARDO, G. F.; ADRIANA, N. R. M.; GALINDO, R. S. A.; ABELARDO, C. M.. Actividad antituberculosa del extracto de Carya illinoensis. Rev Mex Cienc Farm. v. 43, n. 3, p. 36-44, 2012. ISSN: 1870-0195. Disponível em: <http://www.redalyc.org/articulo.oa?id=57928310004>. Acesso em: 19 abr. 2015.

MARTINS, A. G. L. de A.; NASCIMENTO, A. R.; FILHO, J. E. M.; FILHO, N. E. M.; SOUZA, A. G.; ARAGÃO, N. E.; SILVA, D. S. V. DA. Atividade antibacteriana do óleo essencial do manjericão frente a sorogrupos de Escherichia coli enteropatogênica isolados de alfaces. Ciência Rural, Santa Maria, v.40, n.8, p.1791-1796, 2010. ISSN 0103-8478. Disponível em: < http://www.scielo.br/pdf/cr/v40n8/a676cr2539.pdf >. Acesso em: 19 abr. 2015.

MILLEZI, A.F.; BAPTISTA, N. N.; CAIXETA, D. S.; ROSSONI, D. F.; CARDOSO, M. G.; PICCOLI, R. H. Caracterização química e atividade antibacteriana de óleos essenciais de plantas condimentares e medicinais contra Staphylococcus aureus e Escherichia coli. Rev. bras. plantas med., v.16, n.1, p.18-24, 2014. ISSN 1516-0572. Disponível em: <http://www.scielo.br/scielo.php?pid=S1516-05722013000300010\&script=sci_arttext >. Acesso em: 19 abr. 2015. 
MÜLlER, L. G.; PASE, C. S.; RECKZIEGEL, P.; BARCELOS, R. C.; BOUFLEUR, N.; PRADO, A. C.; FETT, R.; BLOCK, J. M.; PAVANATO, M. A.; BAUERMANN, L. F.; DA ROCHA, J. B.; BURGER, M. E.. Hepatoprotective effects of pecan nut shells on ethanolinduced liver damage. Elsevier - Experimental and Toxicologic Pathology. n. 65, p. 165-171, 2013.

NASCIMENTO, G. G. F.; LOCATELLI, J.; FREITAS, P. C.; SILVA, G. L.. Antibacterial activity of plants extracts and phytochemicals on antibiotic-resistant bactéria. Braz J Microbiol, v. 31, n.4, p. 247-256, 2000. ISSN 1517-8382. Disponível em: $<$ http://www.scielo.br/scielo.php?script=sci_arttext\&pid=S1517-83822000000400003 >. Acesso em: 19 abr. 2015.

NATIONAL COMMITTEE FOR CLINICAL LABORATORY STANDARDS - NCCLS. Metodologia dos testes de sensibilidade a agentes antimicrobiana por diluição para bactéria de crescimento aeróbio. Norma aprovada. Brasília: ANVISA; 2003.

NOVAIS, T. S.; COSTA, J. F. O.; DAVID, J. P. L.; DAVID, J. M.; QUEIROZ, L. P.; FRANÇA, F.; GIULIETTI, A. M.; SOARES, M. B. P.; SANTOS, R. R.. Atividade antibacteriana em alguns extratos de vegetais do semi-árido brasileiro. Rev. Bras. Farmacogn., Maringá. v. 13, p. 05-08, 2003. Suplemento 2. ISSN: 0102-695X003. Disponível em: <http://www.scielo.br/scielo.php?script=sci_arttext\&pid=S0102-695X2003000400003>. Acesso em: 19 abr. 2015.

OSÓRIO, E.; FLORESA, M., HERNÁNDEZA, D., VENTURAB, J.; RODRÍGUEZ, R.; AGUILARB, C.. Biological efficiency of polyphenolic extracts from pecan nuts shell (Carya Illinoensis), pomegranate husk (Punica granatum) and creosote bush leaves (Larrea tridentata Cov.) against plant pathogenic fungi. Industrial Crops and Products. v. 31, p. 153-157, 2010. Disponível em: <http://www.sciencedirect.com/science/article/pii/S0926669009001861?np=y>. Acesso em: 19 abr. 2015.

PRADO, A. C. P. Avaliação da atividade antioxidante da casca e torta de noz-pecã [Carya illinoinensis (Wangenh.) C. Koch]. 2008. 131f. Dissertação (Mestrado em Ciência dos Alimentos) - Centro de Ciências Agrárias, Universidade Federal de Santa Catarina - SC, 2008.

PRADO, A. C. Identificação e avaliação da atividade antioxidante e antimicrobiana de compostos fenólicos da casca de noz-pecã [Carya illinoinensis (Wangenh.) C. Koch]. 2013. 243f. Tese (Doutorado em Ciência dos Alimentos) - Universidade Federal de Santa Catarina, Florianópolis - SC, 2013.

PRADO, A. C. P.; ARAGÃO, A. M.; FETT, R.; BLOCK, J. M.. Compostos fenólicos e atividade antioxidante de extratos da casca de noz-pecã [Carya illinoinensis (Wangenh.) C. Koch]. Braz. J. Food Technol., v. 12, n. 4, p. 323-332, 2009. DOI: 10.4260/BJFT2009800900028. Disponível em: <http://www.ital.sp.gov.br/bj/artigos/html/busca/PDF/v12n4397a.pdf>. Acesso em: 19 abr. 2015.

PRETTO, J. B. Potencial antimicrobiano de extratos, frações e compostos puros obtidos de algumas plantas da flora catarinense. 2005. 85f. Dissertação (Mestrado em Ciências Farmacêuticas) - Universidade do Vale do Itajaí, Itajaí -SC, 2005.

RAUHA, J. P.; REMES, S.; HEIMONEN, M.; HOPIA, A.; KAHKONEN, M.; KUJAL, T.; PIHLAJA, K.; VUORELA, P. Antimicrobial efects os finnish plants extrats containing flavonoids and outhers phenolic compounds. International Journal os Food Microbiology, v. 56, p. 3-12, 2000.

RECKZIEGEL, P.; BOUFLEUR, N.; BARCELOS, R. C.; BENVEGNÚ, D. M.; PASE, C. S.; MULLER, L. G.; TEIXEIRA, A. M.; ZANELLA, R.; PRADO, A. C.; FETT, R. BLOCK, J. M.; 
BURGER, M. E.. Oxidative stress and anxiety-like symptoms related to withdrawal of passive cigarette smoke in mice: Beneficial effects of pecan nut shells extract, a by-product of the nut industry. Elsevier - Ecotoxicology and Environmental Safety, n. 74, p. 1770-1778, 2011. Disponível em: <http://www.ncbi.nlm.nih.gov/pubmed/21531023>. Acesso em: 19 abr. 2015.

SANDES, A. R. R.; DI BLASI, G. Biodiversidade e Diversidade Química e Genética. Biotecnologia Ciência \& Desenvolvimento, n.13. p. 28-32, 2000. Disponível em: <http://www.biotecnologia.com.br/revista/bio30/extincao.pdf>. Acesso em: 19 abr. 2015.

SANTOS, N. Q. A Resistência Bacteriana No Contexto Da Infecção Hospitalar. Texto Contexto Enferm; 13(n.esp):64-70. 2004.

SANTOS, L. A.; Determinação da Atividade Antimicrobiana do Extrato Hidroalcoólico da planta Plectranthus Ornatus Codd (Boldo Chinês); Revista da Universidade Vale do Rio Verde, Três Corações, v. 12, n. 1, p 119-129, jan./jul. 2014.

SANTURIO, J. M. Atividade antimicrobiana dos óleos essenciais de orégano, tomilho e canela frente a sorovares de Salmonella enterica de origem avícola. Cienc. Rural. 2007, v.37, n.3, p. 803-808. ISSN 0103-8478. Disponível em: 〈http://www.scielo.br/pdf/cr/v37n3/a31v37n3.pdf〉. Acesso em: 19 abr. 2015.

SANTURIO, D. F. Atividade antibacteriana de óleos essenciais de condimentos sobre E. coli isoladas de suínos, aves e bovinos. 2011. 56f. Dissertação (Dissertação em Ciência e Tecnologia dos Alimentos) - Universidade Federal de Santa Maria, Santa Maria - RS, 2011.

SERRANO, J.; PUUPPONEN-PIMIÃ, R.; DAUER, A.; AURA, A-M.; SAURA-CALIXTO, F. Tannins: Current knowledge of food sources, intake, bioavailability and biological effects. Molecular Nutrition \& Food Research, v. 53, p. 310-S329, 2009. Disponível em: <http://www.ncbi.nlm.nih.gov/pubmed/19437486 >. Acesso em: 19 abr. 2015.

SILVA, M.T.N.; USHIMARU, P. I.; BARBOSA, L. N.; CUNHA, M. L. R. S.; FERNANDES, JUNIOR, A.. Atividade antibacteriana de óleos essenciais de plantas frente a linhagens de Staphylococcus aureus e Escherichia coli isoladas de casos clínicos humanos. Rev. Bras. Pl. Med., Botucatu, v.11, n.3, p.257-262, 2009. Disponível em: $<$ http://www.scielo.br/scielo.php?script=sci_arttext\&pid=S1516-05722009000300005>. Acesso em: 19 abr. 2015.

SCALBERT, A. Antimicrobial properties of tannins. Phytochemistry, v. 30, p. 3875-3883, 1991. Disponível em: < http://www.sciencedirect.com/science/article/pii/003194229183426L>. Acesso em: 19 abr. 2015.

TORO-VAZQUEZ, J.F.; CHARÓ-ALONSO, M. A.; PÉREZ-BRICEÑO, F.. Fatty Acid Composition and Its Relationship with Physicochemical Properties of Pecan (Carya illinoensis) Oil. JAOCS, v. 76, n. 8, p. 957-965, 1999.

TORTORA, G. J.; FUNKE, B. R.; CASE, C. L.(10 Ed.). Microbiologia. Porto Alegre: Artmed, 2012. $934 \mathrm{p}$.

TREVISOL, F.; BENVEGNÚ, D. M.; BARCELOS, R. C. S.; PASE, C. S.; SEGAT, H. J. DIAS, V. T.; DOLCI, G. S.; BOUFLEUR, N.; RECKZIEGEL, P.; BURGER, M. E. Comparative study between two animal modles of extrapyramidal movement disorders: Prevention and reversion by pecan nut shell aqueous extract. Behavioural Brain Research.v. 221, p. 13-18, 2011. DOI: 10.1016/j.bbr.2011.02.026. Disponível em: <http://www.ncbi.nlm.nih.gov/pubmed/21356248>. Acesso em: 19 abr. 2015.

WORLD HEALTH ORGANIZATION - WHO. Combat Antimicrobial Resistance. World Health Day 2011. 
WORLD HEALTH ORGANIZATION - WHO. Public Health Importance of Antimicrobial Resistance. Disponível em: <http://www.who.int/drugresistance/AMR_Importance/en/>. Acesso em: 12 set. 2014.

Recebido em 07/04/2019. Aprovado em 30/09/2019. 